\title{
Importance of baseline cotinine plasma values in smoking cessation: results from a double-blind study with nicotine patch
}

\author{
P. Paoletti*, E. Fornai*, F. Maggiorelli*, R. Puntoni*, G. Viegi*, L. Carrozzi*, \\ A. Corlando*, G. Gustavsson**, U, Säwe**, C. Giuntini*
}

Importance of baseline cotinine plasma values in smoking cessation: results from a double-blind study with nicotine patch. P. Paoletti, E. Fornai, F. Maggiorelli, R. Puntoni, G. Viegi, L. Carrozzi, A. Corlando, G. Gustavsson, U. Säwe, C. Giuntini. (CERS Journals Ltd 1996.

ABSTRACT: Nicotine replacement by transdermal patches is more effective than placebo in smoking cessation, but has a low success rate after one year (9-18\%). We tested whether this was attributed to insufficient nicotine replacement.

We conducted a randomized trial to investigate the effect on outcome of different doses of transdermal nicotine replacement after stratification according to baseline plasma cotinine values. Two hundred and ninety seven adult smokers were enrolled. Those with baseline cotinine $\leq 250 \mathrm{ng} \cdot \mathrm{ml}^{-1}$ (low cotinine) were randomly assigned to placebo (LC-P) or to $15 \mathrm{mg} 16 \mathrm{~h}$ nicotine patches (LC-15), and those with baseline cotinine $>\mathbf{2 5 0} \mathrm{ng} \cdot \mathrm{mL}^{-1}$ (high cotinine) were randomly assigned to 15 mg (HC-15) or 25 mg (HC-25) $16 \mathrm{~h}$ nicotine patches. Plasma nicotine and cotinine values, expired carbon monoxide and withdrawal symptoms were measured at scheduled intervals during treatment.

Smokers in the LC-15 group had a significantly higher success rate than placebo (28 vs 9\%). Smokers with high baseline cotinine had lower success rates, and a high dose of nicotine did not increase success rate (HC-25 9\% vs $\mathrm{HC}-15$ 11\%). Subjects in the HC-15 group had the lowest percentage of nicotine replacement and a higher prevalence of withdrawal symptoms than the HC-25 group. Replacement was similar in groups LC-15 and HC-25, but the success rate was significantly lower in $\mathrm{HC}-25$ group, despite similar levels of withdrawal symptoms.

We conclude that a higher success rate was obtained after one year in smokers with low baseline plasma cotinine values. Determination of plasma cotinine values may be, thus, helpful in identifying smokers who could benefit from transdermal nicotine replacement.

Eur Respir J., 1996, 9, 643-651.
*CNR Institute of Clinical Physiology and 2nd Division of Internal Medicine, University of Pisa, Italy. **Pharmacia, Helsingborg, Sweden.

Correspondence: P. Paoletti

CNR Institute of Clinical Physiology

Via P. Savi 8

56100 Pisa

Italy

\section{P. Paoletti:}

Current address

Eli-Lilly Italy - Medical Division

Via Gramsci, 431

50019 S. Fiorentino (FI)

Keywords: Plasma cotinine

prediction of outcome

smoking cessation

transdermal nicotine replacement

Received: September 161994

Accepted after revision September 28 1995

This work was supported by a grant from Pharmacia: A.C. and F.M. were recipients of a fellowship at the University of Pisa, sponsored by Pharmacia.
The impact of tobacco smoking on human health has recently been reviewed by PETO et al. [1], who estimated about 20 million deaths up to the year 2000 in developed countries. These data clearly confirm the need for active intervention to facilitate smoking cessation.

It is now recognized that smoking, beside its behavioural aspects, is also related to pharmacological dependence on nicotine [2]. The US Surgeon General stated in 1988 that "nicotine is a highly addictive substance comparable in its psychological and physiological properties to other substances of abuse" [3]. Therefore, nicotine replacement has become important in smoking cessation programmes, and most clinical trials have demonstrated its efficacy [4-12]. The use of nicotine chewing gum [5] and, more recently, that of skin patches $[4,6-12]$, as well as nicotine nasal spray [13] and nicotine inhaler [14], have shown higher rates of success when compared with placebo.

Skin patches appear to be a promising tool for nicotine replacement because they are well accepted by smokers and easy to use. Nevertheless, though improvement is significant when compared with placebo $[6,9,12]$ in clinical trials with long-term follow-up, patches have shown a low rate of success after one year (9-25\%).

To improve the rate of cessation it is important to try to understand why about $75-90 \%$ of smokers receiving nicotine replacement relapse within $1 \mathrm{yr}$. One possible explanation of these unsatisfactory results may be inadequate nicotine replacement. The plasma concentration of cotinine, the major metabolite of nicotine, is considered a good measure of nicotine uptake, because of the long half-life of cotinine (15-24 h), the relatively high levels in plasma, and the lack of significant interference by contaminants. HaLl et al. [15] have suggested that this measurement may be useful to categorize smokers entering smoking cessation programmes. Smokers with higher cotinine plasma values may be considered to need higher doses of nicotine replacement. Indeed, a multicentre study in the USA [9] showed a higher rate of success 
in smokers using patches with higher nicotine content than those using lower doses. However, in this study the nicotine dose was randomly assigned, regardless of baseline nicotine-cotinine plasma values. The only published trial in which baseline cotinine levels have been used for individualization of the nicotine dose is an open study performed by TøNNESEN et al. [16], who used three different nicotine doses in subjects who had failed in a previous smoking cessation study. The degree of nicotine replacement was about $50-60 \%$ in each stratification group. The short-term results were moderately encouraging in these hard-core smokers. Indeed, preliminary data by SACHS et al. [17] appear to show that the higher the replacement of nicotine the higher is the cessation rate during nicotine replacement therapy.

Hence, to test whether more adequate nicotine replacement may improve the success rate of smoking cessation, we designed a clinical trial based on different doses of nicotine replacement by skin patches, after stratification of smokers into two groups according to baseline cotinine plasma values. Nicotine and cotinine plasma values were measured throughout the period of treatment to enable retrospective evaluation of the degree of replacement compared with baseline values.

\section{Material and methods}

\section{Enrolment}

Smokers were enrolled from the general population of the city of Pisa $(100,000$ inhabitants, in the region of Tuscany in Central Italy) after publication of an advertisement in the local newspapers. Smokers were invited to contact the staff of the Pulmonary Unit of the Internal Medicine Division.

A computer program was developed to collect information at enrolment and during subsequent visits, to schedule appointments for all participants and to check the internal consistency of the data. Two physicians and two technicians entered data directly on the keyboard. The first interview, by telephone, was devoted to the following admission criteria: age $\geq 20 \mathrm{yrs}$; smoking at least 10 cigarettes per day and for at least $3 \mathrm{yrs}$; being personally motivated to follow the protocol requirements. Smokers with chronic dermatological disorders or cardiac diseases, those receiving treatment with psychotropic drugs, and pregnant and breast-feeding women were not admitted. Three hundred and fifty smokers were selected after the telephone interview, and then after the first visit 297 smokers (mean age $42 \pm 9$ yrs; 179 males and $118 \mathrm{fe}-$ males) were recruited for the clinical trial. Detailed information on smoking history (cigarettes per day, brand of cigarettes to obtain nicotine content, modalities of inhalation, age of starting smoking) were obtained by standard questions.

A blood sample was taken to measure baseline nicotine and cotinine plasma values; nicotine and cotinine were measured by gas chromatography [18].

\section{Study design and treatment}

The design of the study was double-blind and randomized, with parallel groups. Figure 1 shows the scheme of the design and the schedule and duration of treatment.
On the basis of cotinine plasma values, smokers were divided into two treatment groups: $\leq 250 \mathrm{ng} \cdot \mathrm{mL}^{-1}$ (low cotinine - LC) and $>250 \mathrm{ng} \cdot \mathrm{mL}^{-1}$ (high cotinine - HC). This threshold value (median value) was selected on the basis of the distribution of cotinine plasma concentrations obtained from a prescreening representative sample of smokers $(n=200)$ in the city of Pisa, since no data were available on cotinine plasma values in the Italian population.

Smokers with cotinine plasma values $\leq 250 \mathrm{ng} \cdot \mathrm{mL}^{-1}$ were randomly assigned to placebo (LC-P; $n=60$ ) or to $15 \mathrm{mg}$ nicotine patch $(\mathrm{LC}-15 ; \mathrm{n}=60)$. Smokers with cotinine plasma values $>250 \mathrm{ng} \cdot \mathrm{mL}^{-1}$ were randomly assigned to $15 \mathrm{mg}$ nicotine patch $(\mathrm{HC}-15 ; \mathrm{n}=90)$ or to $25 \mathrm{mg}$ nicotine patch $(\mathrm{HC}-25 ; \mathrm{n}=87)$. In order to obtain $25 \mathrm{mg}$ nicotine replacement two patches were used: $15 \mathrm{mg}$ nicotine $\left(30 \mathrm{~cm}^{2}\right.$ patch $)$ and $10 \mathrm{mg}\left(20 \mathrm{~cm}^{2}\right.$ patch). Therefore, to preserve blindness throughout the period of treatment, all subjects used two patches, according to the scheme shown in figure 1.

The nicotine patches contained $0.83 \mathrm{mg} \cdot \mathrm{cm}^{2}$; the release of nicotine was $0.5 \mathrm{mg} \cdot \mathrm{cm}^{2}$ over a period of $16 \mathrm{~h}$. Patches were manufactured and supplied by Consumer Pharma-Pharmacia (Helsingborg, Sweden). The placebo patches did not contain nicotine and were identical in size, colour and other characteristics to the active ones; and, therefore, blindness of the study was maintained.

Patches were applied in the morning and removed at bedtime (worn for $16 \mathrm{~h}$ ), and subjects were asked to apply them to different parts of the body to avoid local skin reactions. Full treatment lasted for 12 weeks and was followed by a 6 -week tapering period (all active groups: $10 \mathrm{mg}\left(20 \mathrm{~cm}^{2}\right) 3$ weeks and $5 \mathrm{mg}\left(10 \mathrm{~cm}^{2}\right) 3$ weeks; placebo groups: corresponding patches).

\section{Visit procedures}

Nicotine and cotinine plasma values were measured at each visit, except for the visit at 6 months, with the aim of retrospectively assessing the degree of replacement during treatment and the consistency of smoking status during follow-up.

At the first visit, a physical examination was performed by one of the physicians and a detailed history of the subject's health was obtained. Blood pressure, body weight, respiratory rate, and expired carbon monoxide (Bedfont monitor, Sittingbourne, UK) were also measured. Subjects were asked to breathe quietly and then, after $10 \mathrm{~s}$ of breath-holding at total lung capacity, to perform a complete slow exhalation. Measurement was performed in our smoke-free Institute within a large hospital area, forbidden to private automobile traffic.

In addition, the instrument for $\mathrm{CO}$ detection in the expired sample allowed a check for zero value before testing each new subject.

A blood sample was also obtained to measure baseline nicotine-cotinine plasma values. All these parameters were obtained during the visit at weeks $1,3,6,12$ and 18 , and at 12 months.

Lung function (forced vital capacity and derived expiratory flows) was measured at enrolment, and at 6 and 12 months to obtain an additional objective tool of the possible beneficial effects of smoking cessation. A computerized dry rolling seal spirometer (Sensor-Medics 


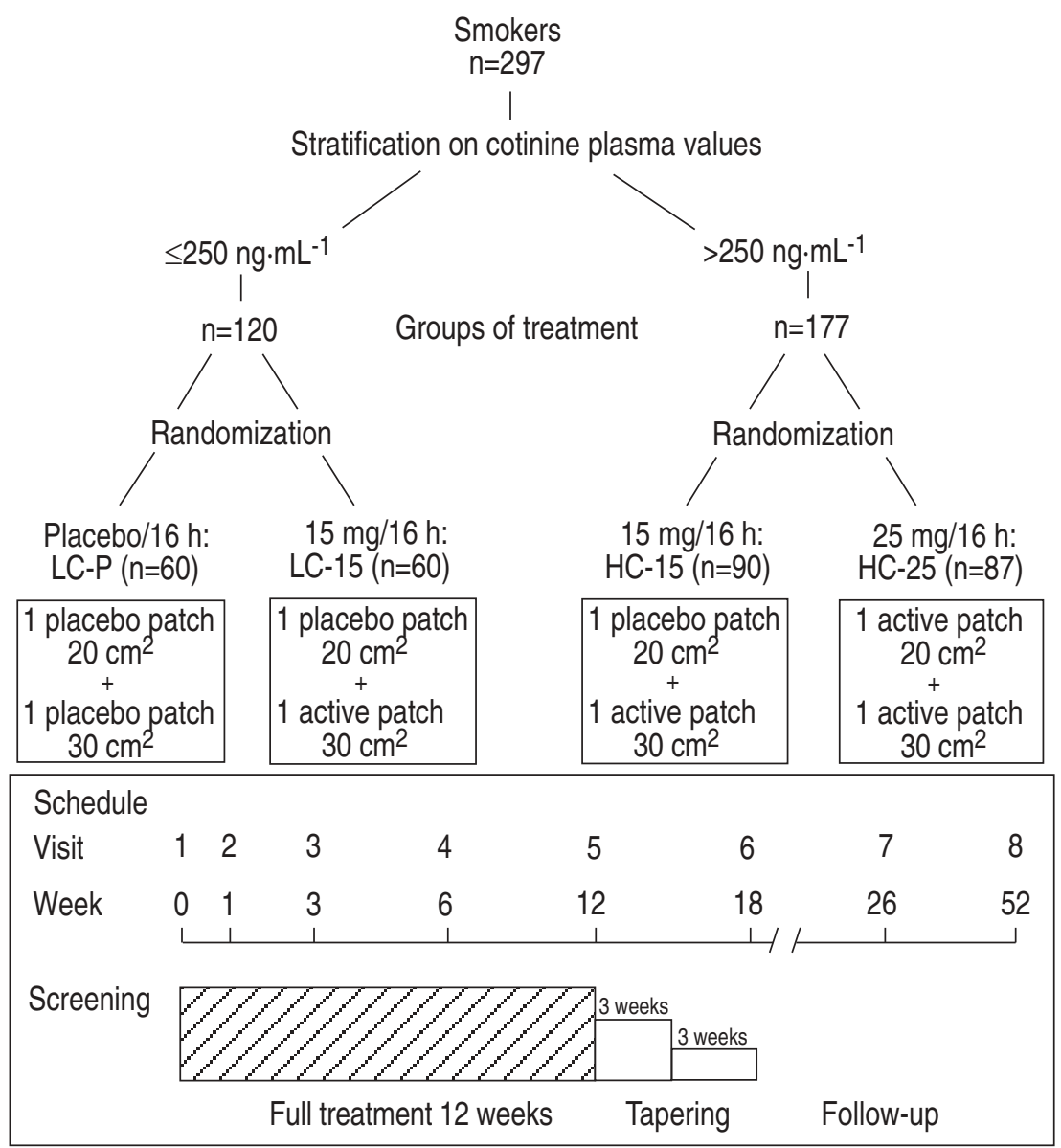

Fig. 1. - Scheme of the experimental design. LC: baseline cotinine $\leq 250 \mathrm{ng} \cdot \mathrm{mL}^{-1}$; LC-P: LC+placebo; LC-15: LC+15 mg active treatment; $\mathrm{HC}$ : baseline cotinine $>250 \mathrm{ng} \cdot \mathrm{mL}^{-1}$; $\mathrm{HC}-15$ : $\mathrm{HC}+15 \mathrm{mg}$ active treatment; $\mathrm{HC}-25: \mathrm{HC}+25 \mathrm{mg}$ active treatment.

model 2130) was used following American Thoracic Society (ATS) recommendations [19].

Psychological questionnaires[20, 21] were administered to determine whether baseline psychological conditions were different among the four groups. Nicotine dependence was evaluated by the Fagerström Tolerance Questionnaire (FTQ) [22].

The presence of systemic side-effects (nausea, vomiting, weakness, headache, palpitations) was evaluated at each visit, together with local skin reactions at the site of application of patches (itching, erythema, oedema and urticaria), using standard questions. A scoring system was used to grade the intensity of these reactions: $0=$ none; $1=$ mild; $2=$ moderate; $3=$ severe. Withdrawal symptoms (craving for smoking, anxiety, irritability, depression, increased appetite, restlessness, insomnia, difficulty in concentrating) were graded using the same scoring system.

All smokers received, at the first visit, a 10 min standard information on health effects of smoking and on general concepts of nicotine addiction. No behavioural intervention was performed.

Success was defined as complete sustained abstinence, self-reported from week 1 up to 12 months and verified by expired $\mathrm{CO}<10 \mathrm{ppm}$ at each visit. Those who did not meet this criterion were considered as failures and divided into two groups: 1 ) occasional smokers = smoking cigarettes, not on a daily basis but occasionally, during the time interval between any two visits; 2) regular smokers $=$ smoking cigarettes on a daily basis. Finally, subjects who did not return for the scheduled visits and were lost to follow up were defined as "drop-outs".

Statistical analyses among the four treatment groups were performed by Chi-squared test for categorical variables and analysis of variance (ANOVA) with the Duncan test for continuous variables. The success rate was evaluated by the generalized Wilcoxon test based on life table analysis. Statistical Package for Social Sciences (SPSS) and System Analyses Statistics (SAS) were used at the Computer Centre of the University of Pisa.

\section{Results}

Table 1 shows the baseline characteristics of the smokers in the four treatment groups. Age, body weight and sex distributions were not different, but the other characteristics varied between smokers of the two stratifications. Within each of the two stratification groups (i.e. LC-P vs LC-15 and HC-15 vs HC-25) characteristics were not different. In addition, there was no significant difference among the groups in terms of personality trends and stress conditions.

In table 2, number of abstainers, occasional and regular smokers together with drop-outs are reported for each visit. Numbers and prevalence rates are based on "point prevalence" analyses. Hence, number of abstainers is different from that used for the analyses to estimate the success in the groups of treatment, which is based on the definition of smoking abstinence from week 1 up to 12 months 
Table 1. - Baseline characteristics of smokers in the four treatment groups

\begin{tabular}{|c|c|c|c|c|c|}
\hline & \multicolumn{2}{|c|}{$\begin{array}{c}\text { Cotinine } \\
\leq 250 \mathrm{ng} \cdot \mathrm{mL}^{-1}\end{array}$} & & \multicolumn{2}{|c|}{$\begin{array}{c}\text { Cotinine } \\
>250 \mathrm{ng} \cdot \mathrm{mL}^{-1}\end{array}$} \\
\hline & $\begin{array}{l}\text { LC-P } \\
(\mathrm{n}=60)\end{array}$ & $\begin{array}{l}\mathrm{LC}-15 \mathrm{mg} \\
\quad(\mathrm{n}=60)\end{array}$ & & $\begin{array}{l}\mathrm{HC}-15 \mathrm{mg} \\
(\mathrm{n}=90)\end{array}$ & $\begin{array}{c}\mathrm{HC}-25 \mathrm{mg} \\
\quad(\mathrm{n}=87)\end{array}$ \\
\hline Age yrs & $44 \pm 10$ & $41 \pm 10$ & & $42 \pm 9$ & $42 \pm 9$ \\
\hline Body weight $\mathrm{kg}$ & $68 \pm 13$ & $74 \pm 11$ & & $77 \pm 11$ & $73 \pm 7$ \\
\hline Male $\%$ & 47 & 58 & & 69 & 62 \\
\hline Cigarettes $\cdot$ day $^{-1}$ & $23 \pm 7$ & $24 \pm 10$ & * & $30 \pm 11$ & $30 \pm 9$ \\
\hline Expired $\mathrm{CO}$ ppm & $19 \pm 7.0$ & $21 \pm 8.7$ & * & $33 \pm 12.5$ & $34 \pm 12.4$ \\
\hline Pack-years n & $24 \pm 13$ & $21 \pm 13$ & * & $29 \pm 15$ & $28 \pm 13$ \\
\hline Nicotine $\mathrm{ng} \cdot \mathrm{mL}^{-1}$ & $10.9 \pm 5.9$ & $11.9 \pm 5.8$ & * & $19.1 \pm 6.0$ & $18.9 \pm 7.6$ \\
\hline Cotinine $\mathrm{ng} \cdot \mathrm{mL}^{-1}$ & $178 \pm 53$ & $184 \pm 46$ & * & $363 \pm 83$ & $355 \pm 91$ \\
\hline FTQ score & $5.4 \pm 2.4$ & $5.2 \pm 2.1$ & * & $7.0 \pm 1.9$ & $7.0 \pm 1.8$ \\
\hline
\end{tabular}

*: $\mathrm{p}<0.05$ by analysis of variance (ANOVA), cotinine $\leq 250 \mathrm{ng} \cdot \mathrm{mL}^{-1}(\mathrm{n}=120) v s$ cotinine $>250 \mathrm{ng} \cdot \mathrm{mL}^{-1}(\mathrm{n}=177)$. FTQ: Fagerström Tolerance Questionnaire; Pack-years: number of cigarettes per day x number of years of smoking/20; LC-P: low cotinine + placebo; LC-15: low cotinine $+15 \mathrm{mg}$ nicotine patch; HC-15: high cotinine $+15 \mathrm{mg}$ nicotine patch; HC-25: high cotinine $+25 \mathrm{mg}$ nicotine patch.

and expired $\mathrm{CO}<10 \mathrm{ppm}$ at each visit. The number of drop-outs increased through the follow-up, as expected, and they are considered as, "failures" for the analyses to estimate the success in the groups of treatment. On the contrary, regular and occasional smokers tended to decrease over time, pointing out that only those who are strongly motivated to quit continue to participate in the study.

Baseline and follow-up values of plasma cotinine and expired $\mathrm{CO}$ are reported in tables 3 and 4 for the 34 abstainers and for the failures (occasional and regular smokers) who participated in the whole trial, respectively. Values are reported after the stratification for the groups of treatment.

In table 3, values of plasma cotinine in the placebo group were always less than $30 \mathrm{ng} \cdot \mathrm{mL}^{-1}$ after the $1 \mathrm{st}$ week, indicating the consistency of smoking cessation; also, values of expired $\mathrm{CO}$ were always $<10 \mathrm{ppm}$. In the other treatment groups, cotinine plasma values after the 1st week were lower than baseline and reflect the nicotine replacement therapy dropping to $<40 \mathrm{ng} \cdot \mathrm{mL}^{-1}$ only after the 18th week; again, expired $\mathrm{CO}$ values were always $<10$ ppm. Values at week 18 were reduced because of the end of nicotine replacement therapy.
In table 4, the same data are reported for failures who attended all the scheduled visits. Cotinine plasma values reflected nicotine intake by cigarette smoking for the placebo group, whilst for the other treatment groups, values reflected the assumption of nicotine from both replacement therapy and cigarette smoking. In this case also values at week 18 were lower because of the reduced nicotine replacement therapy. On the whole, cotinine plasma and expired $\mathrm{CO}$ values after the 1st week were higher than in abstainers. However, they were always lower than at baseline and $\mathrm{CO}$ expired values seldom exceeded 10 ppm.

A significantly higher success rate was reported in the LC-15 group when compared to LC-P (28 vs 9\% after $1 \mathrm{yr} ; \mathrm{p}<0.001$ by generalized Wilcoxon test) (fig. 2). There was no significant difference in abstinence rates between groups HC-15 and HC-25 (11 and 9\%, respectively), and the success rates in these groups were lower than that reported for group LC- 15 .

In order to evaluate the efficacy of the nicotine replacement therapy we have reported cotinine plasma values at baseline and after 1 week of treatment in figure 3. Analyses were performed at week 1 , since most of subjects were still motivated to attend the first control visit, even

Table 2. - Distribution of subjects $(n=297)$ at each visit by smoking characteristics

\begin{tabular}{|c|c|c|c|c|c|c|c|c|}
\hline \multirow[b]{3}{*}{ Week } & \multicolumn{6}{|c|}{ Participants at each visit } & \multicolumn{2}{|c|}{ Drop-outs } \\
\hline & \multicolumn{2}{|c|}{ Abstainers } & \multicolumn{2}{|c|}{$\begin{array}{c}\text { Occasional } \\
\text { smokers }\end{array}$} & \multicolumn{2}{|c|}{$\begin{array}{l}\text { Regular } \\
\text { smokers }\end{array}$} & \multirow[b]{2}{*}{$\mathrm{n}$} & \multirow[b]{2}{*}{$\%^{\#}$} \\
\hline & $\mathrm{n}$ & $\%^{+}$ & $\mathrm{n}$ & $\%^{+}$ & $\mathrm{n}$ & $\%^{+}$ & & \\
\hline 1 & 73 & 25 & 86 & 30 & 132 & 45 & 6 & 3 \\
\hline 3 & 94 & 34 & 68 & 25 & 113 & 41 & 22 & 7 \\
\hline 6 & 90 & 35 & 67 & 26 & 98 & 38 & 42 & 14 \\
\hline 12 & 81 & 38 & 50 & 23 & 82 & 38 & 84 & 28 \\
\hline 18 & 82 & 47 & 31 & 18 & 62 & 35 & 122 & 41 \\
\hline 26 & 75 & 54 & 20 & 14 & 44 & 32 & 158 & 53 \\
\hline 52 & 65 & 67 & 11 & 11 & 21 & 22 & 200 & 67 \\
\hline
\end{tabular}

+: point prevalence analysis, e.g. number of abstainers/number of participants at each visit; \#: percentage of those enrolled at baseline $(n=297)$. 
Table 3. - Baseline and follow-up cotinine plasma concentrations and expired CO in abstainers $(n=34)$

\begin{tabular}{|c|c|c|c|c|c|c|c|c|}
\hline & \multicolumn{2}{|c|}{$\begin{array}{l}\text { LC-P } \\
(n=4)\end{array}$} & \multicolumn{2}{|c|}{$\begin{array}{l}\mathrm{LC}-15 \\
(\mathrm{n}=15)\end{array}$} & \multicolumn{2}{|c|}{$\begin{array}{l}\text { HC-15 } \\
(\mathrm{n}=10)\end{array}$} & \multicolumn{2}{|c|}{$\begin{array}{c}\mathrm{HC}-25 \\
(\mathrm{n}=5)\end{array}$} \\
\hline & $\begin{array}{l}\text { Cotinine } \\
\text { plasma } \\
\mathrm{ng} \cdot \mathrm{mL}^{-1}\end{array}$ & $\begin{array}{c}\text { Expired CO } \\
\text { ppm }\end{array}$ & $\begin{array}{l}\text { Cotinine } \\
\text { plasma } \\
\mathrm{ng} \cdot \mathrm{mL}^{-1}\end{array}$ & $\begin{array}{c}\text { Expired CO } \\
\text { ppm }\end{array}$ & $\begin{array}{l}\text { Cotinine } \\
\text { plasma } \\
\mathrm{ng} \cdot \mathrm{mL}^{-1}\end{array}$ & $\begin{array}{c}\text { Expired CO } \\
\text { ppm }\end{array}$ & $\begin{array}{l}\text { Cotinine } \\
\text { plasma } \\
\mathrm{ng} \cdot \mathrm{mL}^{-1}\end{array}$ & $\begin{array}{c}\text { Expired CO } \\
\text { ppm }\end{array}$ \\
\hline Baseline & $226 \pm 19$ & $21.8 \pm 6.8$ & $174 \pm 52$ & $18.9 \pm 7.9$ & $403 \pm 93$ & $32.4 \pm 11.9$ & $309 \pm 42$ & $22.4 \pm 5.6$ \\
\hline Week 1 & $27 \pm 27$ & $3.8 \pm 1.0$ & $112 \pm 57$ & $4.0 \pm 1.2$ & $128 \pm 34$ & $3.5 \pm 1.1$ & $196 \pm 65$ & $5.4 \pm 2.5$ \\
\hline Week 3 & $30 \pm 39$ & $3.0 \pm 0$ & $109 \pm 50$ & $3.8 \pm 1.5$ & $140 \pm 25$ & $4.9 \pm 2.0$ & $229 \pm 61$ & $4.0 \pm 0.7$ \\
\hline Week 6 & $5 \pm 9$ & $4.3 \pm 1.3$ & $99 \pm 46$ & $3.5 \pm 1.4$ & $136 \pm 52$ & $4.9 \pm 1.2$ & $205 \pm 33$ & $4.4 \pm 1.7$ \\
\hline Week 12 & $5 \pm 5$ & $3.8 \pm 1.3$ & $110 \pm 72$ & $3.0 \pm 1.2$ & $125 \pm 58$ & $3.5 \pm 1.5$ & $155 \pm 66$ & $2.8 \pm 1.3$ \\
\hline Week 18 & $25 \pm 12$ & $1.3 \pm 0.5$ & $36 \pm 23$ & $3.6 \pm 2.1$ & $36 \pm 13$ & $2.9 \pm 1.5$ & $29 \pm 12$ & $4.0 \pm 2.4$ \\
\hline Week 26 & 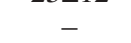 & $3.0 \pm 2.0$ & - & $2.1 \pm 0.8$ & - & $3.1 \pm 1.9$ & - & $2.4 \pm 2.1$ \\
\hline Week 52 & $6 \pm 4$ & $3.8 \pm 0.5$ & $15 \pm 13$ & $3.8 \pm 2.2$ & $6 \pm 5$ & $4.1 \pm 2.0$ & $12 \pm 12$ & $4.2 \pm 1.3$ \\
\hline
\end{tabular}

Values are presented as mean \pm SD. Differences between baseline and values at different visits for cotinine plasma and expired $\mathrm{CO}$ were always significant by analysis of variance (ANOVA). For abbreviations see legend to table. 1

Table 4. - Baseline and follow-up cotinine plasma concentrations and expired $\mathrm{CO}$ in failures (occasional or regular smokers at 1 st week; $n=63$ ) attending all scheduled visits

\begin{tabular}{|c|c|c|c|c|c|c|c|c|}
\hline & \multicolumn{2}{|c|}{$\begin{array}{c}\text { LC-P } \\
(\mathrm{n}=13)\end{array}$} & \multicolumn{2}{|c|}{$\begin{array}{l}\mathrm{LC}-15 \\
(\mathrm{n}=14)\end{array}$} & \multicolumn{2}{|c|}{$\begin{array}{l}\mathrm{HC}-15 \\
(\mathrm{n}=22)\end{array}$} & \multicolumn{2}{|c|}{$\begin{array}{l}\mathrm{HC}-25 \\
(\mathrm{n}=14)\end{array}$} \\
\hline & $\begin{array}{l}\text { Cotinine } \\
\text { plasma } \\
\mathrm{ng} \cdot \mathrm{mL}^{-1}\end{array}$ & $\begin{array}{c}\text { Expired } \mathrm{CO} \\
\text { ppm }\end{array}$ & $\begin{array}{l}\text { Cotinine } \\
\text { plasma } \\
\mathrm{ng} \cdot \mathrm{mL}^{-1}\end{array}$ & $\begin{array}{c}\text { Expired CO } \\
\text { ppm }\end{array}$ & $\begin{array}{l}\text { Cotinine } \\
\text { plasma } \\
\mathrm{ng} \cdot \mathrm{mL}^{-1}\end{array}$ & $\begin{array}{c}\text { Expired CO } \\
\text { ppm }\end{array}$ & $\begin{array}{l}\text { Cotinine } \\
\text { plasma } \\
\mathrm{ng} \cdot \mathrm{mL}^{-1}\end{array}$ & $\begin{array}{c}\text { Expired CO } \\
\text { ppm }\end{array}$ \\
\hline Baseline & $163 \pm 61$ & $17.6 \pm 7.6$ & $171 \pm 48$ & $17.9 \pm 7.1$ & $345 \pm 75$ & $30.5 \pm 15.7$ & $335 \pm 81$ & $28 \pm 7.5$ \\
\hline Week 1 & $23 \pm 17$ & $5.5 \pm 2.9$ & $123 \pm 41$ & $4.6 \pm 2.0$ & $192 \pm 81$ & $10.7 \pm 10.2$ & $195 \pm 60$ & $5.6 \pm 2.0$ \\
\hline Week 3 & $23 \pm 21$ & $4.6 \pm 1.6$ & $124 \pm 49$ & $4.8 \pm 2.0$ & $180 \pm 80$ & $9.0 \pm 9.3$ & $233 \pm 81$ & $5.7 \pm 2.7$ \\
\hline Week 6 & $38 \pm 34$ & $4.0 \pm 3.5$ & $105 \pm 52$ & $3.4 \pm 1.1$ & $155 \pm 75$ & $10.3 \pm 9.5$ & $200 \pm 49$ & $4.7 \pm 2.1$ \\
\hline Week 12 & $32 \pm 31$ & $3.2 \pm 1.9$ & $89 \pm 47$ & $3.3 \pm 1.8$ & $167 \pm 121$ & $8.3 \pm 6.5$ & $188 \pm 70$ & $3.7 \pm 1.5$ \\
\hline Week 18 & $45 \pm 61$ & $5.8 \pm 6.5$ & $29 \pm 15$ & $2.8 \pm 1.2$ & $104 \pm 103$ & $8.9 \pm 6.8$ & $43 \pm 27$ & $4.3 \pm 2.2$ \\
\hline Week 26 & - & $4.8 \pm 4.2$ & - & $2.8 \pm 1.2$ & - & $7.9 \pm 8.3$ & - & $3.4 \pm 2.5$ \\
\hline Week 52 & $67 \pm 82$ & $7.3 \pm 4.6$ & $49 \pm 68$ & $7.6 \pm 5.8$ & $134 \pm 152$ & $15.0 \pm 16.6$ & $71 \pm 78$ & $7.0 \pm 4.8$ \\
\hline
\end{tabular}

Differences between baseline and values at different visits for cotinine plasma values and expired CO were always significant by analysis of variance. For abbreviations see legend to table. 1

a)

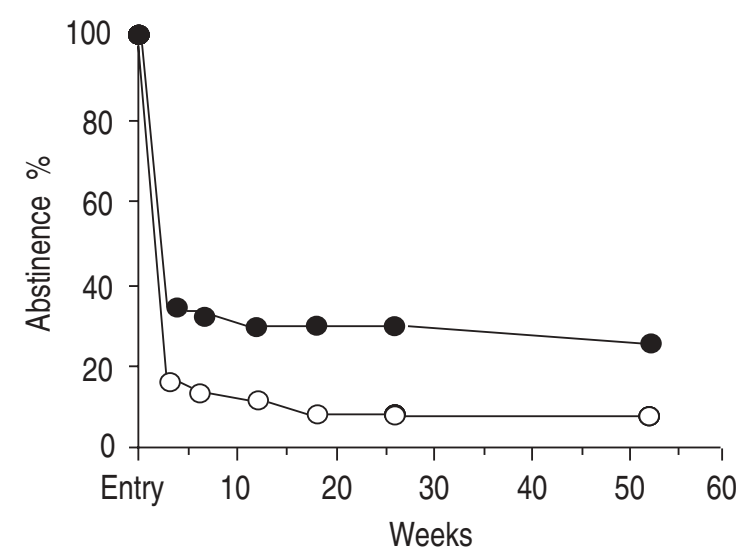

b)

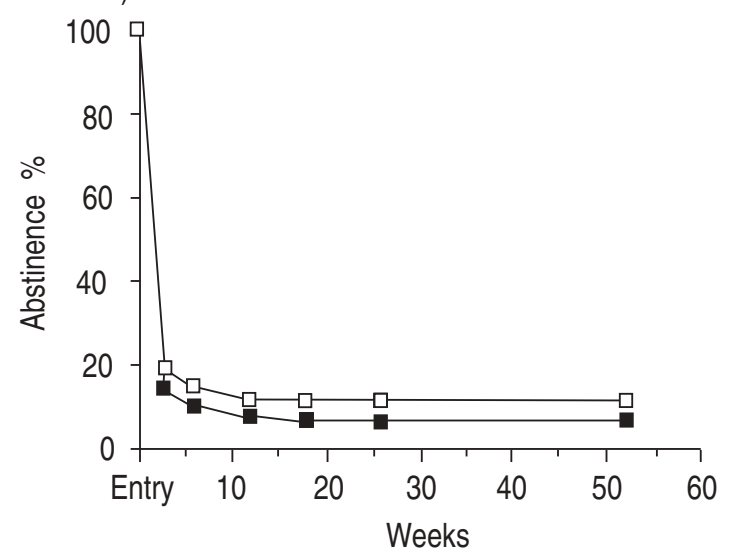

Fig. 2. - Abstinence from week 3 in each of the four treatment groups, considering separately the two groups of stratification based on cotinine

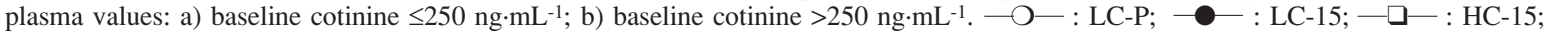
HC-25. 
those still smoking. In abstainers, percentage replacement (based on baseline cotinine plasma values) reached more than $50 \%$ in the LC- 15 and HC- 25 groups, but in the $\mathrm{HC}-15$ group percentage replacement was lower $(35 \%)$, and in the LC-P group the cotinine concentration was, as expected, close to zero.

The effect of additional smoking during treatment is evident. In all treatment groups, cotinine plasma values during nicotine replacement were higher than in abstainers, but lower than baseline cotinine values. Similar results were also obtained at the other visits (see data in tables 3 and 4).

Finally, we evaluated the effect of nicotine replacement on some abstinence symptoms (fig. 4). Irritability score was higher in group HC-15 than LC-15 $(\mathrm{p}<0.05)$; difference in $\mathrm{HC}-15$ vs $\mathrm{HC}-25$ was significant at borderline level $(\mathrm{p}=0.08)$. Craving for smoking tended to be higher in groups HC-15 and LC-P, but the differences were not significant. There were no differences in systemic adverse reactions among the treatment groups. For instance, there were few conditions (including mild

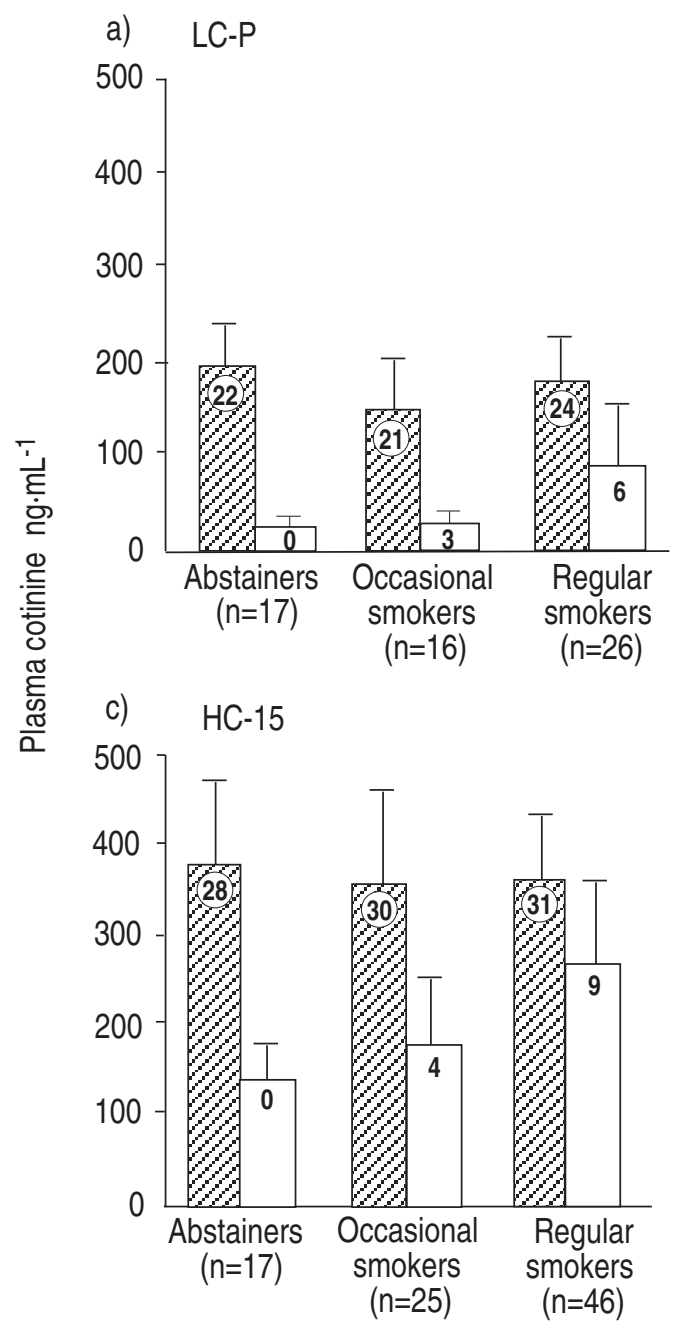

degree) reported by more than $10 \%$ of subjects: itching (40\% with active $v s 20 \%$ with placebo patches; $\mathrm{p}=0.0076$ ); weakness (11 vs 8\%, $\mathrm{p}=0.71)$; erythema (12 vs $12 \%, \mathrm{p}=$ 0.85 ); headache (13 vs 10\%, $\mathrm{p}=0.066)$; stomach upset (11 vs 7\%, $\mathrm{p}=0.50)$; sleep disturbance (13 vs 24\%; $\mathrm{p}=$ 0.049). The most frequent local adverse event, itching, was reported in the first days of treatment and then disappeared in most cases; however, it was reported as important in 4 subjects (1.3\% of all participants). Heart rate and blood pressure were not affected by the different treatments.

Based on a value $>10 \%$ of days not using the patch in the interval between pairs of subsequent control visits, six subjects out of 291 had not worn the patches regularly at week 1 , as well as 29 subjects out of 213 at week 12 (i.e. end of full-treatment period). Thus, the compliance for treatment was $98 \%$ at week 1 and $86 \%$ at week 12 .

Mean values of forced expiratory volume in one second (FEV1)\% predicted [23] was $104 \pm 17 \%$ and there was no difference among the four groups of treatment. Fifty one

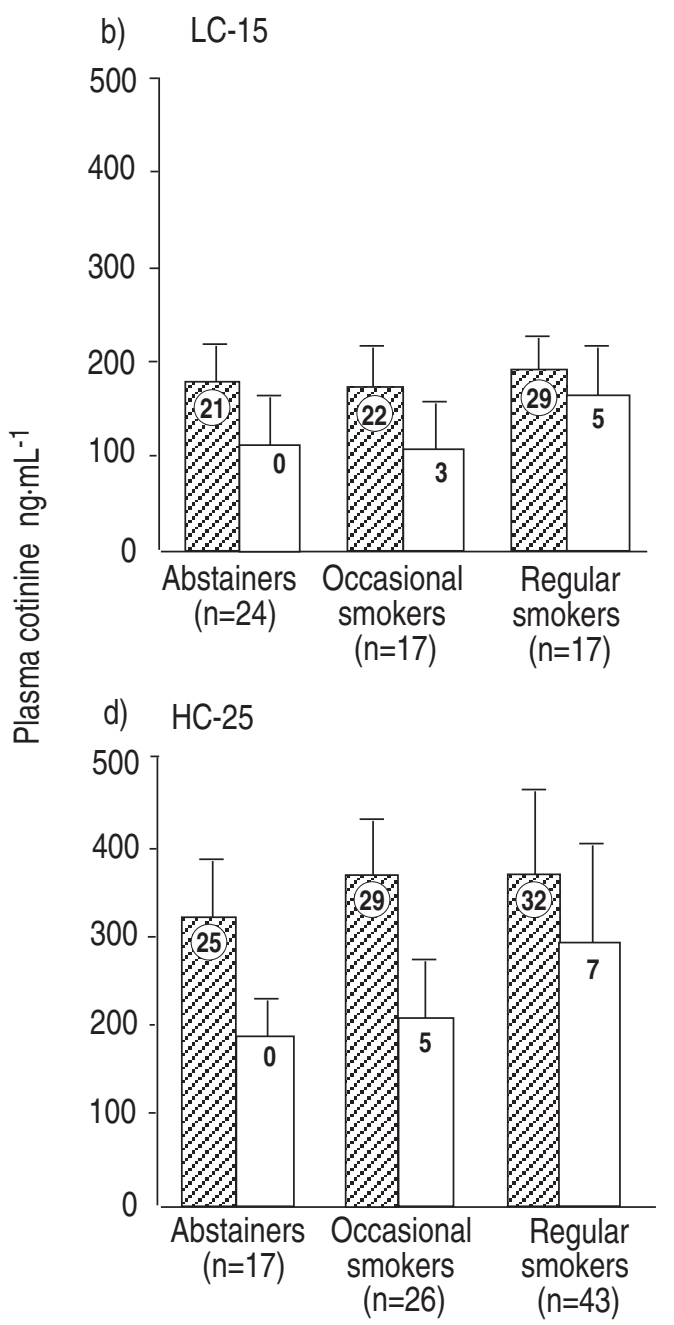

Fig. 3. - Plasma cotinine concentrations (mean \pm SD) at baseline and after 1 week of treatment in each of the four treatment groups: a) baseline low cotinine LC-P; b) baseline low cotinine LC-15; c) baseline high cotinine HC-15; d) baseline high cotinine HC-25. Numbers in the hatched columns represent mean daily cigarette consumption at enrolment. Numbers in white columns represent either mean daily cigarette consumption during treatment for regular smokers, or the ratio between cigarette consumption and time interval between visits for occasional smokers. Difference between values at baseline and after 1 week was significant by analysis of variance (ANOVA) for different smoking classifications and in the four groups of treatment. $\mathscr{Z}$ : baseline; $\square$ : treatment. For abbreviations see legend to figure 1. 

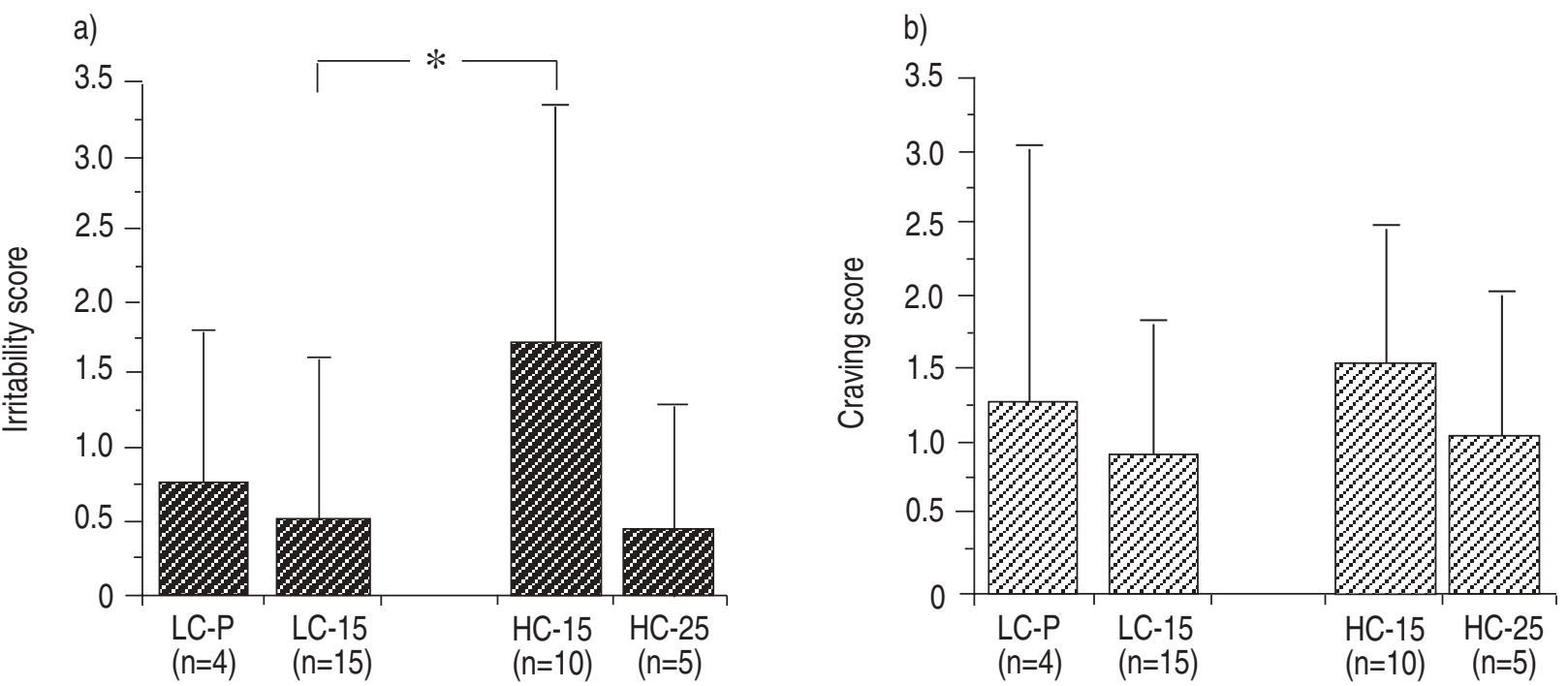

Fig. 4. - Withdrawal symptoms as: a) mean ( $\pm \mathrm{SD})$ irritability score; and b) mean cigarette craving score after 1 week of treatment in abstainers in each of the four groups. *: p $<0.05$ (analysis of variance (ANOVA)-Duncan test). For abbreviations see legend to figure 1.

smokers had a FEV1/forced vital capacity (FVC) ratio $<70 \%$ : these subjects were equally distributed among drop-outs (19\%), failures (14\%) and abstainers (15\%) (no significant difference by Chi-squared test).

\section{Discussion}

This study demonstrates that after $1 \mathrm{yr}$ of treatment in subjects with low baseline cotinine plasma values, smoking cessation may be attained in $28 \%$ of smokers receiving nicotine replacement by transdermal patches, compared to $9 \%$ receiving placebo. This result is similar to that of SACHS et al. [8] and Hurt et al. [24]. However, behavioural interventions were provided in both these studies.

In smokers with higher baseline cotinine plasma values, the rate of success was lower, but there was no difference between the two treatment groups.

When results from the three active treatment groups were pooled, the overall success rate was $17 \%$, which is similar to other studies using patches [4-7, 9-11]. This observation suggests that the relatively low success rate observed in previous trials may be ascribed to the presence of smokers with different baseline characteristics (e.g. cotinine plasma values). Our study showed that smokers with higher baseline cotinine plasma values had a lower success rate (i.e. $11 \%$ for $\mathrm{HC}-15$ and $9 \%$ for HC-25), and this was not affected by a dose increase from 15 to $25 \mathrm{mg}$ nicotine. The design of the study deliberately did not include a placebo treatment in the high cotinine plasma values group, since many reports have already demonstrated the efficacy of nicotine replacement therapy when compared to placebo [4, 6-10]. Hence, for ethical reasons we decided to provide these heavy smokers with some nicotine and to compare $15 \mathrm{mg}$ nicotine versus $25 \mathrm{mg}$ nicotine replacement.

It is interesting to note that smokers of HC-25 showed a lower success rate, in spite of having the same degree of replacement (about 57\%) as the LC-15. Furthermore, considering only subjects with high baseline cotinine values (i.e. $\mathrm{HC}-15$ and $\mathrm{HC}-25$ ), there was an association between success rate and degree of substitution: $60 \%$ of abstainers were in the group with higher degree of substitution, $27 \%$ and $0 \%$ in the intermediate groups, and $13 \%$ in the group with lower degree of substitution $(p<0.01$, with Chi-squared test). Our results suggest that these subjects may need a modification to the treatment plan: increase of the dose of patches, regulation of dose after 1 or more weeks, or other types of nicotine replacement (chewing gum or nasal spray) singly or in combination.

The importance of measuring baseline cotinine plasma values when starting smoking cessation programmes has been suggested by our results. In addition to the possibility of identifying smokers who would have more difficulty in quitting smoking, it also allows identification of those in whom nicotine replacement may have a higher probability of success. Recent observations by SACHS et al. [8], Kenford et al. [25] and Stapleton et al. [26] show that the probability of success is related to the baseline cotinine plasma values; smokers with lower values have a higher probability of success. In addition, SACHS et al. [17] pointed out that the rate of success is related to the rate of nicotine replacement.

One might argue that cotinine measurement is costly and might be replaced by simpler tools such as FTQ or number of cigarettes smoked daily.

However, although statistically significant, the correlation coefficients of the linear regression analysis of baseline cotinine plasma value with FTQ and number of cigarettes smoked daily were low $(r=0.41$ and 0.35 , respectively), and percentages of explained variance were 17 and $12 \%$, respectively.

The degree of nicotine replacement after one week (fig. 3) was the same in the low baseline cotinine group receiving $15 \mathrm{mg}$ and the high cotinine group receiving $25 \mathrm{mg}$ (57\%), but substantially lower in the high cotinine group receiving $15 \mathrm{mg}$ nicotine $(36 \%)$. Table 3 shows that the degree of nicotine replacement appears quite constant during the whole treatment period in abstainers and, in addition, values of expired $\mathrm{CO}$ are similar in the same period for all treatment groups.

The pattern of cotinine plasma values in failures during the period of treatment, reported in table 4 , confirm 
the data shown in figure 3, where data are presented separately for occasional and regular smokers. Cotinine plasma values are affected by the additional intake of nicotine due to smoking cigarettes. Nevertheless, cotinine plasma values were always lower than baseline values. It is interesting to point out that values of expired $\mathrm{CO}$ are consistently low and often $<10 \mathrm{ppm}$, which is considered the threshold values to define smoking cessation, pointing out the limitation of this method to define the success.

The two groups with the highest level of replacement had the same degree of craving and irritability in spite of the difference in cotinine baseline values (fig. 4). The placebo group and the high cotinine group with $15 \mathrm{mg}$ both experienced more withdrawal symptoms.

It is important to point out that additional smoking (occasional and, mainly, regular smoking) was able to increase the cotinine plasma values. A consistent reduction of daily cigarette consumption was obtained in all treatment groups, but regular smokers in the high cotinine group receiving $15 \mathrm{mg}$ of treatment smoked more cigarettes per day (HC-15=9 $\pm 8, \mathrm{HC}-25=7 \pm 7$, and LC$15=5 \pm 5$ cigarettes $\cdot$ day $\left.^{-1}\right)$. This observation suggests a dose-response trend (i.e. the lower the nicotine replacement, the greater the number of cigarettes smoked). In addition, in the presence of similar nicotine replacement, smokers with higher baseline cotinine (HC-25) need more cigarettes to achieve cotinine values similar to baseline. Furthermore, it is interesting to note that baseline mean daily cigarette consumption was lower in abstainers of the three active treatment groups, when compared with those who continued to smoke. It suggests that, within each treatment group, smokers who succeeded in quitting were those who smoked fewer cigarettes at the beginning of treatment.

We have collected no information on passive smoking. However, we think that the effect of passive smoking on active smokers is minor, and that the possible additional effect of passive smoking on nonsmokers of this study is unlikely to be an important bias for cotinine plasma values. As shown by JARVIS et al. [27], cotinine plasma values in nonsmokers exposed to passive smoking are lower $\left(1.81-2.52 \mathrm{ng} \cdot \mathrm{mL}^{-1}\right)$ than urinary values (6.50-9.36 ng. $\left.\mathrm{mL}^{-1}\right)$ and are not correlated with selfreported quantity of exposure to passive smoking. Overall, these cotinine values are very low, when compared to those found in our subjects enrolled in the smoking cessation trial.

The prevalence of withdrawal symptoms was significantly higher in group $\mathrm{HC}-15$, i.e. subjects with the lowest level of nicotine replacement. In fact, in the same group, those who smoked regularly had the highest levels of expired $\mathrm{CO}$ and smoked the greatest number of cigarettes per day. It is important, however, to point out that the long-term smoking cessation findings in the two high cotinine groups were not influenced by the early effects on withdrawal symptoms.

The results indicate that subjects react differently to nicotine replacement when it is given as a transdermal patch. Those with low initial plasma cotinine appear to benefit from a standard dose of transdermally applied nicotine; however, higher doses may increase the success.

It is also important to point out that subjects who smoked whilst wearing their nicotine patches had lower cotinine values compared to baseline values: this indicates that they have substantially reduced their smoking and also that it does not seem likely that they expose themselves to dangerous levels of nicotine. There was no increase in adverse reactions in this group and there was a consistent pattern of reduction throughout the treatment period.

Since dose-response relationships have been clearly demonstrated between the number of cigarettes consumed and the risk of developing lung cancer, chronic obstructive pulmonary disease, and heart disease [2830], smoking reduction may be considered as being partially successful, but still important. Although the main goal must be complete cessation, the impact on health consequences of possible sustained smoking reduction, by nicotine replacement, should be considered in the future.

As regards lung function, few smokers enrolled in this study showed marked airflow limitation, and the presence of $\mathrm{FEV} 1 / \mathrm{FVC}<70 \%$ did not appear to influence the success rate.

In our study, smokers who were able to quit showed a trend to a lower $\triangle F E V 1$ over the 1 year study period $\left(180 \pm 632 \mathrm{~mL} \cdot \mathrm{yr}^{-1} ; \mathrm{n}=34\right)$ when compared to smokers who completed the study $\left(240 \pm 844 \mathrm{~mL} \cdot \mathrm{yr}^{-1} ; \mathrm{n}=63\right)$. Although a $1 \mathrm{yr}$ time interval is very short to correctly estimate the longitudinal decline of FEV1, this beneficial effect of smoking cessation may be important. In fact, this observation may be used as an additional objective result to encourage and reinforce motivation to quit in subjects enrolled in cessation programmes.

In conclusion, the analyses in this study suggest the importance of measuring cotinine plasma values not only at baseline, but also during treatment, in order to assess the degree of nicotine replacement and, consequently, to increase or to reduce doses and to change or to add other nicotine administration devices.

Although our data needs to be confirmed by other studies, on the basis of our observations, measurement of baseline plasma cotinine should be considered to characterize smokers who wish to quit smoking. Hence, our recommendation is to develop a fast, easy, and reliable method of measuring cotinine plasma values with the aim of extending its use in smoking cessation programmes and, consequently, improving the knowledge of the characteristics of smokers and the possibility of success.

Finally, the results of our trial illustrate the importance of baseline cotinine plasma values in identifying smokers who may benefit from nicotine replacement by transdermal patches. Moreover, these results suggest the possibility of increasing the dose administered through patches.

Acknowledgements: The authors thank D. Molesti (University of Pisa) for data collection; U. Mammini, F. Celiano, M. Martinelli (CNUCE, Pisa) for computer assistance in data collection and statistical analyses, and P. Silvi for the secretarial assistance and the typing of manuscript.

\section{References}

1. Peto R, Lopez AD, Boreham J, Thun M, Heath C Jr. Mortality from tobacco in developed countries: indirect estimation from national vital statistics. Lancet 1992; 339: $1268-1278$. 
2. Prignot J. Pharmacological approach to smoking cessation. Eur Respir J 1989; 2: 550-560.

3. US Department of Health and Human Services. Nicotine addiction. A report of the Surgeon General, USA, 1988.

4. Abelin T, Buehler A, Muller B, Vesanen K, Imhof PR. Controlled trial of transdermal nicotine patch in tobacco withdrawal. Lancet 1989; 1: 7-10.

5. Tønnesen P, Fryd V, Hansen M, et al. Effect of nicotine chewing gum in combination with group counseling on the cessation of smoking. N Engl J Med 1988; 318: $15-18$.

6. Tønnesen P, Norregaard J, Simonsen K, et al. A doubleblind trial of a 16 hour transdermal nicotine patch in smoking cessation. N Engl J Med 1991; 325: 311-315.

7. Hurt RD, Lauger GG, Offord KP, Kottke TE, Dale LC. Nicotine-replacement therapy with use of a transdermal nicotine patch - a randomized double-blind placebocontrolled trial. Mayo Clin Proc 1990; 65: 1529-1537.

8. Sachs DPL, Säwe U, Leischow SJ. Effectiveness of a 16 hour transdermal nicotine patch in a medical practice setting, without intensive group counseling. Arch Intern Med I993; I53: 1881-1890.

9. Transdermal Nicotine Study Group. Transdermal nicotine for smoking cessation. J Am Med Assoc 1991; 266: 3133-3138.

10. Russell MAH, Stapleton JA, Feyerabend C, et al. Targeting heavy smokers in general practice: randomised controlled trial of transdermal nicotine patches. $\mathrm{Br}$ Med $\mathrm{J}$ 1993; 306: 1308-1312.

11. Imperial Cancer Research Fund General Practice Research Group. Effectiveness of a nicotine patch in helping people stop smoking: results of a randomized trial in general practice. Br Med J 1993; 306: 1304-1308.

12. Daughton DM, Heatley SA, Prendergast JJ, et al. Effect of transdermal nicotine delivery as an adjunct to lowintervention smoking cessation therapy. Arch Intern Med 1991; 151: 749-752.

13. Sutherland G, Stapleton JA, Russell MAH, et al. Randomised controlled trial of nasal nicotine spray in smoking cessation. Lancet 1992; 340: 324-329.

14. Tønnesen P, Norregaard J, Mikkelsen K, Jorgensen S, Nilsson F. A double-blind trial of a nicotine inhaler for smoking cessation. J Am Med Assoc 1993; 269: 12681271.

15. Hall SM, Herning RI, Jones RT, Benowitz NL, Jacob P III. Blood cotinine levels as indicators of smoking treatment outcome. Clin Pharmacol Ther 1984; 35: 810-814.

16. Tønnesen P, Norregaard J, Säwe U, Simonsen K. Recycling with nicotine patches in smoking cessation. Addiction 1993; 88: 533-539.
17. Sachs DPL, Benowitz NL, Bostrom AG, Hansen MD. Percent serum replacement and success of nicotine patch therapy. Am J Respir Crit Care Med 1995; 151: A688.

18. Feyerabend C, Russell MAH. A rapid gas-liquid chromatographic method for the determination of cotinine and nicotine in biological fluids. J Pharm Pharmacol 1990; 42: 450-452.

19. American Thoracic Society. Standardization of spirometry: 1987 update. Am Rev Respir Dis 1987; 136: $1285-1298$.

20. Kellner R, Sheffield B. A self-rating scale of distress. Psychol Med 1973; 3: 88-100.

21. Eysenck HY, Eysenck SBG. In: Manual of Eysenck Personality Inventory. Sevenoaks, England, Hodder \& Stoughton, 1975.

22. Fagerström KO, Schneider NG. Measuring nicotine dependence: a review of the Fagerström Tolerance Questionnaire. J Behav Med 1989; 12: 159-182.

23. Paoletti P, Pistelli G, Fazzi P, et al. Reference values for vital capacity and flow-volume curves from a general population study. Bull Eur Physiopathol Respir 1986; 22: 451-459.

24. Hurt RD, Dale LC, Fredrickson PA, et al. Nicotine patch therapy for smoking cessation combined with physician advice and nurse follow-up. One-year outcome and percentage of nicotine replacement. J Am Med Assoc 1994; 271: 596-600.

25. Kenford SL, Fiore MC, Jorenby DE, Smith SS, Wetter D, Baker TB. Predicting smoking cessation. Who will quit with and without nicotine patch. J Am Med Assoc 1994; 271: 589-594.

26. Stapleton JA, Russell MAH, Feyerabend C, et al. Dose effects and predictors of outcome in a randomized trial of transdermal nicotine patches in general practice. Addiction 1995; 90: 31-42.

27. Jarvis M, Tunstall-Pedoe H, Feyerabend C, Vesey C, Saloojee Y. Biochemical markers of smoke absorption and self-reported exposure to passive smoking. J Epidemiol Commun Health 1984; 38: 335-339.

28. Doll R, Peto R. Mortality in relation to smoking: 20 years' observations on male British doctors. $\mathrm{Br} \mathrm{Med} \mathrm{J}$ 1976; 2: 1525-1536.

29. Dockery DW, Speizer FE, Ferris BG Jr, et al. Cumulative and reversible effects of lifetime smoking on simple tests of lung function in adults. Am Rev Respir Dis 1988; 137: 286-292.

30. US Department of Health and Human Services. Health consequences of smoking: cardiovascular disease, a report of the Surgeon General. Public Health Service, Office on Smoking and Health, Rockville, Maryland 20857, 1983. 